\title{
Announcement
}

\section{The First European Conference} on Psychotherapy Research 17-20 September 1981

This conference was stimulated and is sponsored by the Society For Psychotherapy Research (U.S.A.) - an international, multidisciplinary, scientific organization. The Society For Psychotherapy Research, founded in 1968 as an independent organization is dedicated to the scientific study of psychotherapy, its purpose is to encourage the systematic study of psychological principles underlying personality and behaviour change resulting from psychotherapeutic intervention.

Professor Michael Gelder, Warneford Hospital, Oxford, is the European Vice-President.

Organizer of the conference WOLF-RUDIGER MINSEL,

Department of Education, University of Trier, Federal Republic of Germany.
Mailing addresses and further details DORIS GORES, University of Trier, Department of Education, Tarforst, D-5500 Trier, Federal Republic of Germany. 